\title{
FIFTH IPCC ASSESSMENT REPORT NOW OUT
}

\author{
ZBIGNIEW W. KUNDZEWICZ \\ Institute of Agricultural and Forest Environment \\ Polish Academy of Sciences \\ Bukowska 19, 60-809 Poznań, Poland \\ kundzewicz@yahoo.com
}

\begin{abstract}
The Fifth Assessment Report (AR5) of the Intergovernmental Panel on Climate Change (IPCC) is now available. It provides policymakers with an assessment of information on climate change, its impacts and possible response options (adaptation and mitigation). Summaries for policymakers of three reports of IPCC working groups and of the Synthesis Report have now been approved by IPCC plenaries. This present paper reports on the most essential findings in AR5. It briefly informs on the contents of reports of all IPCC working groups. It discusses the physical science findings, therein observed changes (ubiquitous warming, shrinking cryosphere, sea level rise, changes in precipitation and extremes, and biogeochemical cycles). It deals with the drivers of climate change, progress in climate system understanding (evaluation of climate models, quantification of climate system responses), and projections for the future. It reviews impacts, adaptation and vulnerability, including observed changes, key risks, key reasons for concern, sectors and systems, and managing risks and building resilience. Finally, mitigation of climate change is discussed, including greenhouse gas emissions in the past, present and future, and mitigation in sectors. It is hoped that the present article will encourage the readership of this journal to dive into the AR5 report that provides a wealth of useful information.
\end{abstract}

KEY WORDS: Intergovernmental Panel on Climate Change (IPCC), climate change, climate change impacts, adaptation, mitigation, scenarios, projections. 


\section{INTRODUCTION}

The mandate of the Intergovernmental Panel on Climate Change (IPCC) is to provide policymakers with an objective assessment of the scientific, technical and socio-economic information available in regard to climate change, its impacts and possible response options (adaptation and mitigation). The IPCC does not carry out research, and nor does it monitor climate-related data or other relevant parameters. It bases its assessment mainly on peer-reviewed and published scientific and technical literature. Repeat issuing of an updated assessment, in which old and new information is blended, aids decisionmakers with improving their orientation in the light of new evidence arising.

The Fifth IPCC Assessment Report (AR5) is now available. Summaries for Policymakers of reports of three Working Groups (WGs) have been approved by plenaries, as follows: WG I: The Physical Science Basis - in September 2013; WG II: Impacts, Adaptation and Vulnerability; and WG III: Mitigation of Climate Change - in April 2014.

Each report consists of the following set of products: a (lengthy) report proper, a technical summary, and a summary for policymakers. Reports (AR5) of all three Working Groups are now freely available in the public domain on the Internet: http://www.ipcc.ch/report/ar5/. A printed publication from Cambridge University Press is available, at cost.

The final product of the suite of IPCC AR5, i.e. the Synthesis Report, was approved in November 2014.

The present contribution informs the reader as to IPCC AR5 and its principal findings. The selection of material and its interpretation have been a matter for the author, though the paper draws heavily on the AR5 body. While few actual citation marks are used, this paper does in fact contain many direct citations from AR5.

The most important attribution statement has been subject to considerable evolution in the course of the five consecutive IPCC assessment reports (1990-2013). It reads, respectively:

First Assessment Report (FAR 1990): "little evidence of detectable anthropogenic influence on climate".

Second Assessment Report (SAR 1995): "discernible human influence on climate".

Third Assessment Report (TAR 2001): "most of the observed warming over the last 50 years is likely to have been due to the increase in greenhouse gas concentrations".

Fourth Assessment Report (AR4 2007): "most of the observed increase in globally averaged temperatures since the mid-20 th century is very likely due to the observed increase in anthropogenic greenhouse gas concentrations".

Fifth Assessment Report (AR5 2013): "It is extremely likely that more than half of the observed increase in global average surface temperature from 1951 to 2010 
was caused by the anthropogenic increase in greenhouse gas concentrations and other anthropogenic forcings together".

The qualifiers "likely", "very likely", and "extremely likely", in the last three statements were defined to correspond with respective probabilities in excess of 66, 90 and $95 \%$.

There is a well-defined and calibrated uncertainty language - qualifiers accompany every substantial statement in AR5. The degree of certainty in key findings is based on the author teams' evaluations of underlying scientific understanding, and is expressed as a qualitative level of confidence and, when possible, probabilistically with a quantified likelihood (as exemplified by the attribution statements cited above). Confidence in the validity of a finding is based on the evidence and the degree of agreement. Probabilistic estimates of quantified measures of uncertainty in a finding are based on statistical analysis of observations or model results, or both, and expert judgment. All this is very important for the scientific rigor, but contributes to the length of the IPCC document and somewhat disturbs the flow, rendering reading rather difficult. In the present review of the principal findings, uncertainty and confidence expressions are mostly omitted, on purpose - for simplicity. Also, it is common for AR5 to give a range of values (uncertainty band) rather than a single crisp value, representing a "best estimate". In the present paper, such a best estimate is often given without the uncertainty band. Interested readers can easily find the complete information in the AR5 products.

\section{SCENARIOS}

A new set of four scenarios, denoted Representative Concentration Pathways (RCPs), was used, wherever possible, in AR5, replacing the SRES scenarios (Nakićenović and Swart 2000) used in earlier IPCC assessment reports. The new scenarios were used for the new climate model simulations carried out under the framework of the Coupled Model Intercomparison Project Phase 5 (CMIP5) of the World Climate Research Programme. In all RCPs, atmospheric $\mathrm{CO}_{2}$ concentrations are higher in 2100 relative to the present day as a result of a further increase of cumulative emissions of $\mathrm{CO}_{2}$ to the atmosphere during the $21^{\text {st }}$ century.

The RCPs are identified by their approximate total radiative forcing in the year 2100 relative to $1750: 2.6 \mathrm{~W} \mathrm{~m}^{-2}$ for $\mathrm{RCP} 2.6,4.5 \mathrm{~W} \mathrm{~m}^{-2}$ for $\mathrm{RCP} 4.5,6.0 \mathrm{~W} \mathrm{~m}^{-2}$ for RCP6.0, and $8.5 \mathrm{~W} \mathrm{~m}^{-2}$ for RCP8.5, comparing with extrapolation of business-asusual. For the CMIP5 results, these values should be understood as indicative only, as the climate forcing resulting from all drivers varies between models due to specific model characteristics and treatment of short-lived climate forcings. These four RCPs include one mitigation scenario leading to a very low forcing level (RCP2.6), two stabilization scenarios (RCP4.5 and RCP6), and one scenario with very high greenhouse gas emissions (RCP8.5). The RCPs can thus represent a range of climate policies, as compared with the no-climate policy of the SRES scenarios used earlier. 


\section{THE PHYSICAL SCIENCE BASIS 1}

\section{OBSERVED CHANGES}

\section{Warming}

Warming of the climate system of the Earth is unequivocal, and since the 1950s, many of the observed changes have been unprecedented over time scales of decades to millennia. The atmosphere and ocean have warmed, the amounts of snow and ice have diminished, sea level has risen, and concentrations of greenhouse gases have increased.

The globally averaged combined land and ocean surface temperature data as calculated by a linear trend, show a warming of 0.85 (0.65 to 1.06$){ }^{\circ} \mathrm{C}$, over the period 1880 to 2012, for which multiple independently produced datasets exist. Almost the entire globe has experienced surface warming (Fig. 1).

In addition to robust multi-decadal warming, global mean surface temperature exhibits substantial decadal and inter-annual variability that renders trends based on short-term records very sensitive to the beginning and end dates. For instance, the warming over $1998-2012$ amounting to 0.05 (-0.05 to 0.15$){ }^{\circ} \mathrm{C}$ per decade, is relatively weak. However, this is so, because this period begins in a very warm year with a strong El Niño event.

Continental-scale surface temperature reconstructions show, with high confidence, multi-decadal periods during the Mediaeval Climate Anomaly (year 950 to 1250) that were in some regions as warm as in the late $20^{\text {th }}$ century, but did not occur as coherently across regions.

Ocean warming dominates the increase in energy stored in the climate system, accounting for more than 90\% of the energy accumulated between 1971 and 2010, therein two thirds in the upper ocean $(0-700 \mathrm{~m})$. On a global scale, the ocean warming is greatest near the surface - the upper $75 \mathrm{~m}$ warmed by 0.11 (from 0.09 to 0.13 ) ${ }^{\circ} \mathrm{C}$ per decade over the period 1971 to 2010.

1 According to IPCC Assessment Report 2013 (IPCC 2013). 


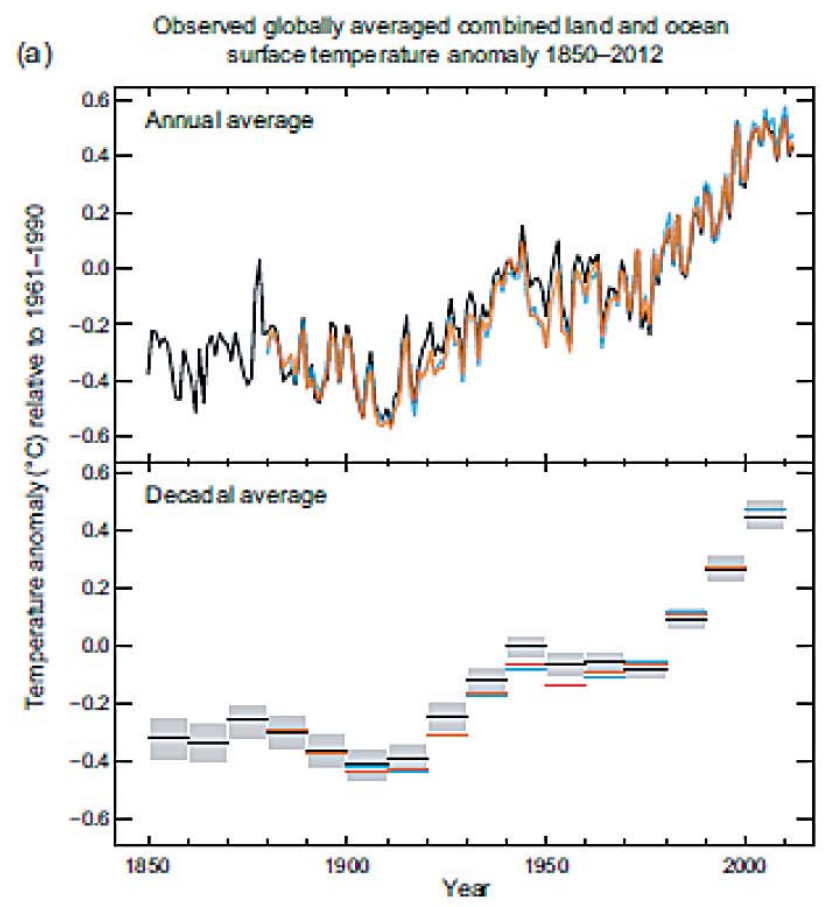

(b)

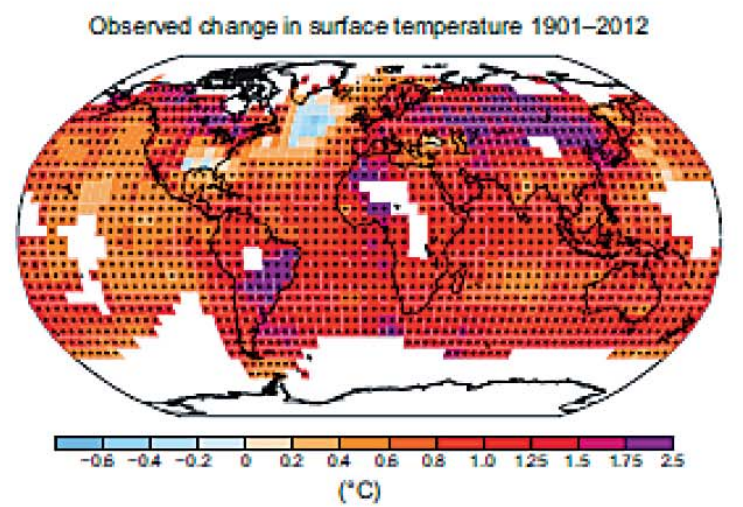

Figure 1. (a) - Observed global mean combined land and ocean surface temperature anomalies, from 1850 to 2012 from three datasets

Top panel: annual mean values. Bottom panel: decadal mean values including the estimate of uncertainty for one dataset (black). Anomalies are relative to the mean for 1961-1990. (b) - Map of the observed surface temperature change from 1901 to 2012 derived from temperature trends determined by linear regression from one dataset (orange line in panel (a). Trends have been calculated where data availability permits a robust estimate (i.e. only for grid boxes with greater than $70 \%$ completeness of records and more than $20 \%$ data availability in the first and last $10 \%$ of the time period). Other areas are white. Grid boxes for which the trend is significant at the $10 \%$ level are indicated by a + sign. (Source: IPCC 2013). 


\section{A shrinking cryosphere}

Over the last two decades, the Greenland and Antarctic ice sheets have been losing mass, glaciers have continued to shrink, and Arctic sea ice and Northern Hemisphere spring snow cover have continued to decrease in extent.

The average rate of ice loss from glaciers around the world, excluding glaciers on the periphery of ice sheets, increased by more than $21 \%$ between study periods (1971 to 2009) and (1993 to 2009).

The average rate of ice loss from the Greenland ice sheet increased nearly 7-fold between the periods (1992 to 2001) and (2002 to 2011), while the average rate of ice loss from the Antarctic ice sheet increased nearly 5-fold. This latter loss was mainly from the northern Antarctic Peninsula and the Amundsen Sea sector of West Antarctica.

The annual mean Arctic Sea ice extent decreased over the period 1979 to 2012 at a rate in the range 3.5 to $4.1 \%$ per decade and 9.4 to $13.6 \%$ per decade for the summer sea ice minimum (perennial sea ice), while the annual mean Antarctic sea ice extent increased (sic!) at a rate in the range of 1.2 to $1.8 \%$ per decade.

The extent of Northern Hemisphere snow cover has decreased and permafrost temperatures have increased in most regions. In the Russian European North, a considerable reduction in permafrost thickness and areal extent has been observed.

\section{Sea level}

The rate of sea-level rise since the mid-19th century has been higher than the mean rate characterising the previous two millennia. There was a transition in the late $19^{\text {th }}$ to early $20^{\text {th }}$ centuries from relatively low mean rates of rise to higher rates of rise. Over the period 1901 to 2010, global mean sea level rose by approx. $0.19 \mathrm{~m}$. The mean rate of global averaged sea level rise was $1.7 \mathrm{~mm} \mathrm{yr}^{-1}$ between 1901 and 2010, $2.0 \mathrm{~mm} \mathrm{yr}^{-1}$ between 1971 and 2010, and $3.2 \mathrm{~mm} \mathrm{yr}^{-1}$ between 1993 and 2010.

Over the period 1993 to 2010, global mean sea level rise has been consistent with the sum of the observed contributions from ocean thermal expansion due to warming $\left(1.1 \mathrm{~mm} \mathrm{yr}^{-1}\right)$, changes in glaciers $\left(0.76 \mathrm{~mm} \mathrm{yr}^{-1}\right)$, the Greenland ice sheet $(0.33 \mathrm{~mm}$ $\left.\mathrm{yr}^{-1}\right)$, the Antarctic ice sheet $\left(0.27 \mathrm{~mm} \mathrm{yr}^{-1}\right)$, and land water storage $\left(0.38 \mathrm{~mm} \mathrm{yr}^{-1}\right)$. The sum of these contributions slightly exceeds $2.8 \mathrm{~mm} \mathrm{yr}^{-1}$ (in comparison to the estimate of $3.2 \mathrm{~mm} \mathrm{yr}^{-1}$ given above).

\section{Precipitation and extremes}

Averaged over the mid-latitude land areas of the Northern Hemisphere, precipitation has increased since 1901, but confidence is medium before 1951 and high afterwards.

Changes in many extreme weather and climate events have been observed. Warm extremes (e.g. number of warm days and nights, frequency of heat waves) are on the rise, while cold extremes (e.g. number of cold days and nights) are on the decrease. The frequency or intensity of heavy precipitation events has likely increased in North America and Europe. 


\section{Carbon and other biogeochemical cycles}

The atmospheric concentrations of the greenhouse gases: carbon dioxide $\left(\mathrm{CO}_{2}\right)$, methane $\left(\mathrm{CH}_{4}\right)$, and nitrous oxide $\left(\mathrm{N}_{2} \mathrm{O}\right)$ have all increased since 1750. In 2011 the concentrations of these greenhouse gases were $391 \mathrm{ppm}$ (parts per million), $1803 \mathrm{ppb}$ (parts per billion, 1 billion =1,000 million), and $324 \mathrm{ppb}$, respectively, and exceeded the pre-industrial levels by about $40 \%, 150 \%$, and $20 \%$.

Concentrations of $\mathrm{CO}_{2}, \mathrm{CH}_{4}$, and $\mathrm{N}_{2} \mathrm{O}$ now substantially exceed the highest concentrations ever recorded in ice cores during the past 800000 years. The mean rates of increase in atmospheric concentrations over the past century are unprecedented in the last 22000 years.

Ocean acidification is quantified by a decrease in the $\mathrm{pH}$ of ocean surface water by 0.1 since the beginning of the industrial era, corresponding to a $26 \%$ increase in hydrogen ion concentration.

\section{DRIVERS OF CLIMATE CHANGE}

Natural and anthropogenic substances and processes that alter the Earth's energy budget are drivers of climate change. Radiative forcing (RF) quantifies the change in energy fluxes caused by changes in these drivers from pre-industrial times through to the present. Positive RF leads to surface warming, negative RF leads to surface cooling.

The best estimate for the total anthropogenic RF for 2011 relative to 1750 is $2.29 \mathrm{~W} \mathrm{~m}^{-2}$. The value of RF has increased more rapidly since 1970 than during prior decades.

The portion of RF that results from changes in concentrations in well-mixed greenhouse gases $\left(\mathrm{CO}_{2}, \mathrm{CH}_{4}, \mathrm{~N}_{2} \mathrm{O}\right.$, and Halocarbons) is $2.83 \mathrm{~W} \mathrm{~m}^{-2}$. Emissions of $\mathrm{CO}_{2}$ alone and of $\mathrm{CH}_{4}$ alone have caused an $\mathrm{RF}$ of $1.68 \mathrm{~W} \mathrm{~m}^{-2}$ and $0.97 \mathrm{~W} \mathrm{~m}^{-2}$, respectively.

The RF of the total aerosol effect in the atmosphere, which includes cloud adjustments due to aerosols, is $-0.9 \mathrm{~W} \mathrm{~m}^{-2}$ and results from a negative forcing from most aerosols and a positive contribution from black carbon absorption of solar radiation. Aerosols and their interactions with clouds have offset a substantial portion of global mean forcing from well-mixed greenhouse gases, and continue to contribute the largest uncertainty to the total RF estimate.

The total natural RF from solar irradiance changes and stratospheric volcanic aerosols made only a small contribution to the net radiative forcing, except for brief periods (of the order of a year or two) after large volcanic eruptions.

\section{UNDERSTANDING THE CLIMATE SYSTEM}

The understanding of recent changes in the climate system results from the combining of observations, the study of feedback processes, and model simulations. 
More detailed and longer observations and improved climate models are now available.

\section{Evaluation of climate models}

Human influence on the climate system is clear. This is evident from the increasing greenhouse gas concentrations in the atmosphere, positive radiative forcing, observed warming, and understanding of the climate system.

Climate models have improved and now reproduce observed continental-scale surface temperature patterns and trends over many decades, including the more rapid warming since the mid-20 th century and the cooling immediately following large volcanic eruptions.

The long-term climate model simulations show a trend in global-mean surface temperature from 1951 to 2012 that agrees with the observed trend, even if there are differences between simulated and observed trends over part of this period (e.g., from 1998 to 2012).

\section{Quantification of climate system responses}

Observational records and model studies of temperature change, climate feedbacks and changes in the Earth's energy budget together provide confidence in the magnitude of global warming in response to the sum of forcings. The net feedback from the combined effect of changes in water vapour, and differences between atmospheric and surface warming is positive, and therefore amplifies changes in climate. The net radiative feedback due to all cloud types combined is likely positive, with uncertainty regarding the impact of warming on low clouds.

As mentioned already, the AR5 contains a stronger attribution statement that any of the earlier IPCC reports. Human influence has been detected in warming of the atmosphere and the ocean, in changes in the global water cycle, in reductions in snow and ice, in global mean sea-level rise, and in changes in some climate extremes.

Greenhouse gases contributed a global mean surface warming likely to be in the range of $0.5^{\circ} \mathrm{C}$ to $1.3^{\circ} \mathrm{C}$ over the period 1951 to 2010 , with the contributions from other anthropogenic forcings, including the cooling effect of aerosols, likely to be in the range $-0.6^{\circ} \mathrm{C}$ to $0.1^{\circ} \mathrm{C}$. The contribution from natural forcings is likely to be in the range $-0.1^{\circ} \mathrm{C}$ to $0.1^{\circ} \mathrm{C}$, and that attributable to natural internal variability in the range $-0.1^{\circ} \mathrm{C}$ to $0.1^{\circ} \mathrm{C}$. Together these assessed contributions are consistent with the observed warming of approximately $0.6^{\circ} \mathrm{C}$ to $0.7^{\circ} \mathrm{C}$ over this period.

It is very likely that anthropogenic forcings have made a substantial contribution to increases in global upper ocean heat content $(0-700 \mathrm{~m})$, and have affected the global water cycle (observed increases in atmospheric moisture content, global-scale changes in precipitation patterns over land, intensification of heavy precipitation over land, and changes in surface and sub-surface ocean salinity). 


\section{PROJECTIONS FOR THE FUTURE}

Models simulate climate change on the basis of a set of scenarios of anthropogenic forcings, indicating that continued emissions of greenhouse gases will cause further warming, and changes in all components of the climate system. Substantial and sustained reductions of greenhouse gas emissions will be required to limit climate change.

The global mean surface temperature change for the period 2016-2035 relative to $1986-2005$ will likely be in the range $0.3^{\circ} \mathrm{C}$ to $0.7^{\circ} \mathrm{C}$, assuming that there will be no major volcanic eruptions or secular changes in total solar irradiance, while for $2081-2100$ it will likely be in the ranges $0.3^{\circ} \mathrm{C}$ to $1.7^{\circ} \mathrm{C}(\mathrm{RCP} 2.6), 1.1^{\circ} \mathrm{C}$ to $2.6^{\circ} \mathrm{C}$ (RCP4.5), $1.4^{\circ} \mathrm{C}$ to $3.1^{\circ} \mathrm{C}$ (RCP6.0) or $2.6^{\circ} \mathrm{C}$ to $4.8^{\circ} \mathrm{C}$ (RCP8.5). The Arctic region will warm more rapidly than the global mean, and mean warming over land will be greater than over the ocean.

Relative to the average from years 1850 through to 1900 , global surface temperature change by the end of the $21^{\text {st }}$ century is projected to likely exceed $1.5^{\circ} \mathrm{C}$ for RCP4.5, RCP6.0 and RCP8.5, i.e. for all RCP scenarios except RCP2.6. Warming is likely to exceed $2^{\circ} \mathrm{C}$ for RCP6.0 and RCP8.5, but unlikely to exceed $2^{\circ} \mathrm{C}$ for RCP2.6. Warming is unlikely to exceed $4^{\circ} \mathrm{C}$ for RCP2.6, RCP4.5 and RCP6.0.

Warming will continue to exhibit interannual-to-decadal variability and will not be uniform regionally.

The global ocean will continue to warm during the $21^{\text {st }}$ century. Heat will penetrate from the surface to the deep ocean and affect ocean circulation. Best estimates of ocean warming in the top 100 meters are of about $0.6^{\circ} \mathrm{C}$ (RCP2.6) to $2.0^{\circ} \mathrm{C}$ (RCP8.5).

The Arctic sea ice cover will continue to shrink and thin and Northern Hemisphere spring snow cover will decrease as global mean surface temperature rises and global glacier volume decreases further.

Global mean sea level will continue to rise, with increasing rate of sea-level rise, due to increased ocean warming and increased loss of mass from glaciers and ice sheets. Global mean sea-level rise for 2081-2100 relative to 1986-2005 will likely be in the ranges 0.26 to $0.55 \mathrm{~m}$ for $\mathrm{RCP} 2.6,0.32$ to $0.63 \mathrm{~m}$ for $\mathrm{RCP} 4.5,0.33$ to $0.63 \mathrm{~m}$ for RCP6.0, and 0.45 to $0.82 \mathrm{~m}$ for RCP8.5.

Changes in the global water cycle will not be uniform. The contrast in precipitation between wet and dry regions and between wet and dry seasons will increase. Extreme precipitation events are projected to become more intense and more frequent.

Climate change will affect carbon cycle processes in a way that will exacerbate the increase of $\mathrm{CO}_{2}$ concentration in the atmosphere. Further uptake of carbon by the ocean will increase ocean acidification. Cumulative emissions of $\mathrm{CO}_{2}$ will largely determine global mean surface warming. Most aspects of climate change will persist for many centuries even if emissions of $\mathrm{CO}_{2}$ are stopped - there is a substantial multi-century climate change commitment created by past and present emissions of $\mathrm{CO}_{2}$. 


\section{IMPACTS, VULNERABILITY, AND ADAPTATION²}

\section{OBSERVED CHANGES}

Changes in climate have affected impacts on natural and human systems. In many regions, changing precipitation or melting snow and ice have altered hydrological systems and water resources. Many species have shifted their geographic ranges, seasonal activities, migration patterns, abundances, and species interactions in response to ongoing climate change. Negative impacts of climate change on crop yields have been more common than positive impacts. Climate change has negatively affected wheat and maize yields for many regions and in the global aggregate. Several periods of rapid food and cereal price increases following climate extremes in key producing regions indicate a sensitivity of markets to climate extremes.

Differences in vulnerability and exposure arise from non-climatic factors and from inequalities often produced by uneven development processes that shape differential risks from climate change.

Impacts from recent climate-related extremes, such as heat waves, droughts, floods, cyclones, and wildfires, reveal significant vulnerability and exposure of some ecosystems and many human systems to current climate variability. Climate-related hazards exacerbate other stressors, often with negative outcomes for livelihoods, especially for people living in poverty.

Uncertainties about future vulnerability, exposure, and responses of interlinked human and natural systems continue to be large.

\section{KEY RISKS}

There are a range of key risks, spanning sectors and regions:

- Risk of death, injury, ill-health, or disrupted livelihoods in low-lying coastal zones and small islands, due to storm surges, coastal flooding, and sea-level rise;

- Risk of severe ill-health and disrupted livelihoods for large urban populations due to inland flooding in some regions;

- Systemic risks due to extreme weather events leading to breakdown of infrastructure networks and critical services such as electricity, water supply, and health and emergency services;

- Risk of mortality and morbidity during periods of extreme heat, particularly for vulnerable urban populations and those working outdoors;

- Risk of food insecurity and the breakdown of food systems linked to warming, drought, flooding, and precipitation variability and extremes, particularly for poorer populations;

2 According to IPCC Assessment Report, 2014 (IPCC 2014a). 
- Risk of loss of rural livelihoods and income due to insufficient access to drinking and irrigation water and reduced agricultural productivity, particularly in less developed semi-arid regions;

- Risk of loss of marine, coastal, terrestrial and inland water ecosystems, biodiversity, and the ecosystem goods, functions, and services they provide for livelihoods.

Many key risks constitute particular challenges for the Least Developed Countries and vulnerable communities, given their limited ability to cope.

\section{REASONS FOR CONCERN}

Five integrative reasons for concern (Fig. 2) provide a framework for summarizing key risks across sectors and regions, illustrating the implications of warming and of adaptation limits for people, economies, and ecosystems. All temperatures below are given as global average temperature change relative to 1986-2005 (understood as "recent").

Unique and threatened systems - Some unique and threatened systems, including ecosystems and cultures, are already at risk from climate change. The number of such systems at risk of severe consequences increases with additional warming. Many species and systems with limited adaptive capacity are subject to very high risks with additional warming above $2^{\circ} \mathrm{C}$, particularly Arctic sea ice and coral reef systems.

Extreme weather events - Climate-change-related risks from extreme events, such as heat waves, extreme precipitation, and coastal flooding, are already moderate and will be high with $1^{\circ} \mathrm{C}$ additional warming. Risks associated with some types of extreme events (e.g. extreme heat) increase further at higher temperatures.

Distribution of impacts - Risks are unevenly distributed, and generally greater for disadvantaged people and communities. Risks are already moderate because of regionally-differentiated climate-change impacts on crop production in particular. Based on projected decreases in regional crop yields and water availability, risks of unevenly distributed impacts are high for additional warming above $2{ }^{\circ} \mathrm{C}$.

Global aggregate impacts - Risks of global aggregate impacts are moderate for additional warming between $1-2^{\circ} \mathrm{C}$, reflecting impacts to both Earth's biodiversity and the overall global economy. Extensive biodiversity loss with associated loss of ecosystem goods and services results in high risks around $3{ }^{\circ} \mathrm{C}$ additional warming. Aggregate economic damage accelerates with increasing temperature, but few quantitative estimates have been completed for additional warming of $3^{\circ} \mathrm{C}$ or above.

Large-scale singular events - With increasing warming, some physical systems or ecosystems may be at a risk of abrupt and irreversible changes that is moderate between $0-1{ }^{\circ} \mathrm{C}$ additional warming (e.g. irreversible regime-shifts in warm-water coral reef and Arctic ecosystems). Risks increase disproportionately as temperature increases further, and become high above $3^{\circ} \mathrm{C}$. For sustained warming greater than some threshold, near-complete loss of the Greenland Ice Sheet would occur over a millennium or more, contributing up to $7 \mathrm{~m}$ of global sea-level rise. 


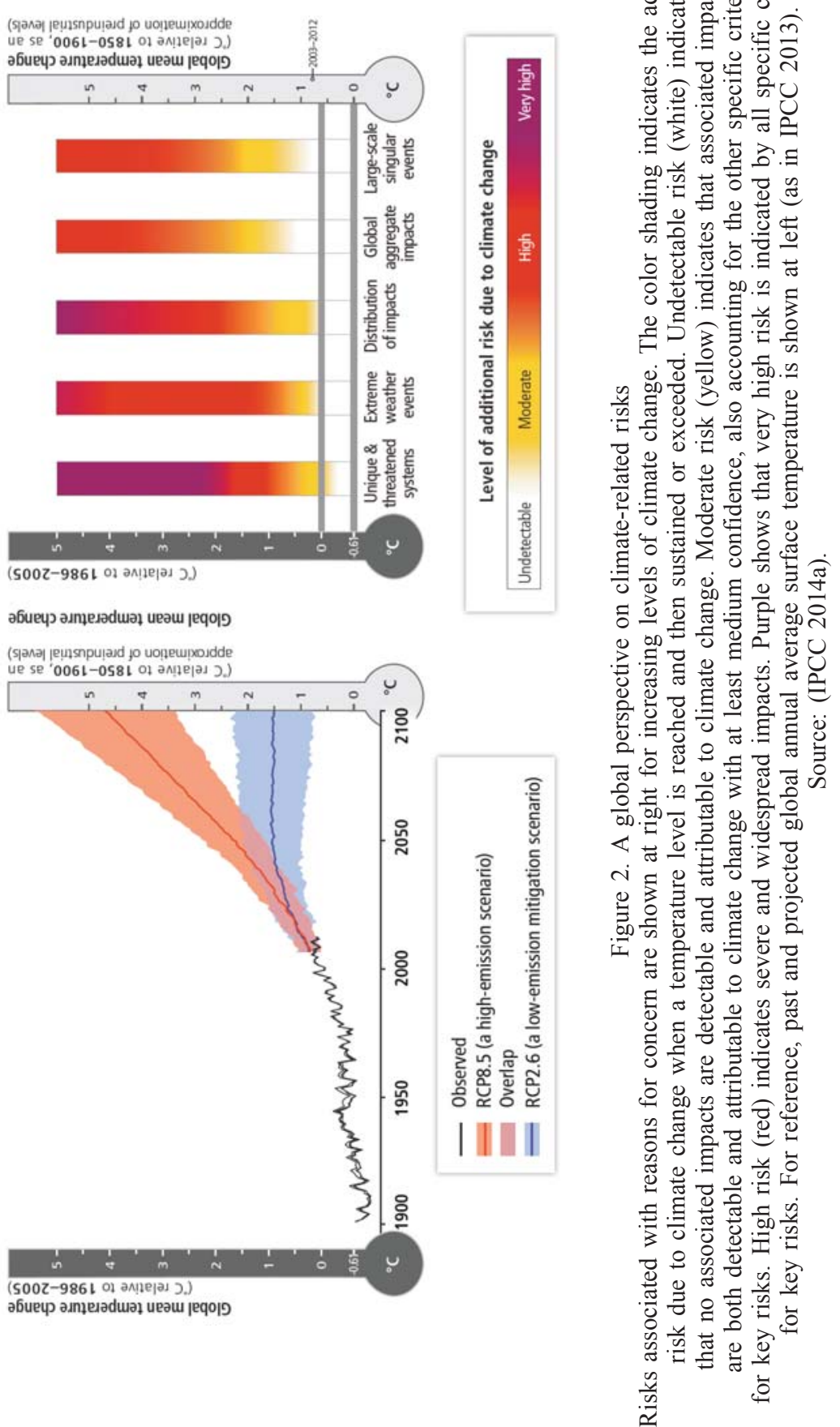


Increasing magnitudes of warming increase the likelihood of severe, pervasive, and irreversible impacts. The overall risks of climate-change impacts can be reduced by limiting the rate and magnitude of climate change.

\section{SECTORS AND SYSTEMS}

Freshwater-related risks of climate change increase significantly with increasing greenhouse gas concentrations. The fraction of the global population experiencing water scarcity and the fraction affected by major river floods increase with the level of warming in the $21^{\text {st }}$ century. Climate change is projected to reduce renewable water resources significantly in most dry subtropical regions, intensifying competition for water among sectors. In presently-dry regions, drought frequency will increase, whilst - in contrast - water resources will increase at high latitudes.

A large fraction of both terrestrial and freshwater species faces increased extinction risk under projected climate change, especially as climate change interacts with other stressors, such as habitat modification, over-exploitation, pollution, and invasive species. Within this century, magnitudes and rates of climate change associated with medium- to high-emission scenarios (RCP4.5, 6.0, and 8.5) pose a high risk of abrupt and irreversible regional-scale change in the composition, structure, and function of terrestrial and freshwater ecosystems, including wetlands.

Due to sea-level rise, coastal systems and low-lying areas will increasingly experience adverse impacts such as submergence, coastal flooding, and coastal erosion. Due to projected climate change, global marine species redistribution and marine biodiversity reduction in sensitive regions will challenge the sustained provision of fisheries productivity and other ecosystem services. For medium- to high-emission scenarios, ocean acidification poses substantial risks to marine ecosystems, especially polar ecosystems and coral reefs, associated with impacts on the physiology, behaviour, and population dynamics of individual species from phytoplankton to animals.

For the major crops (wheat, rice, and maize) in tropical and temperate regions, climate change without adaptation is projected to impact production negatively for local temperature increases of $2{ }^{\circ} \mathrm{C}$ or more above late- $20^{\text {th }}$-century levels, although individual locations may benefit.

Many global risks of climate change are concentrated in urban areas, where more than $52 \%$ of the global population lived in 2011. By 2050, the urban population is expected to constitute $64-69 \%$ of world population. Major future rural impacts are expected, through impacts on water availability and supply, food security, and agricultural incomes, including shifts in production areas of food and non-food crops across the world.

Projected climate change will impact upon human health by exacerbating health problems that already exist, but will also lead to increases in ill-health in many regions, and especially in developing countries with low income, as compared with a baseline without climate change. 
Global economic impacts from climate change are difficult to estimate. Estimates vary in their coverage of subsets of economic sectors and depend on a large number of assumptions, many of which are disputable. With these recognised limitations, the incomplete estimates of global annual economic losses for additional temperature increases of $\sim 2{ }^{\circ} \mathrm{C}$ are between 0.2 and $2.0 \%$ of income. Additionally, there are large differences between and within countries. Losses accelerate with greater warming. Estimates of the incremental economic impact of emitting carbon dioxide lie between a few dollars and several hundreds of dollars per tonne of carbon. Estimates vary strongly with the assumed damage function and discount rate.

For most economic sectors, the impacts of non-climatic drivers, such as changes in population, age structure, income, technology, relative prices, lifestyle, regulation, and governance are projected to be large relative to the impacts of climate change.

Climate change over the $21^{\text {st }}$ century is projected to increase displacement of people and can indirectly increase risks of violent conflicts by amplifying drivers of these conflicts, such as poverty and economic shocks.

The impacts of climate change on the critical infrastructure and territorial integrity of many states are expected to influence national security. For example, land inundation due to sea-level rise poses risks to the territorial integrity of small-island states and states with extensive coastlines. Some transboundary impacts of climate change, such as changes in sea ice, shared water resources, and pelagic fish stocks, have the potential to increase rivalry among states.

Throughout the $21^{\text {st }}$ century, climate-change impacts are projected to slow economic growth, make poverty reduction more difficult, further erode food security, and prolong existing poverty traps, while creating new ones, particularly in urban areas and emerging hotspots of hunger.

\section{MANAGING RISKS AND BUILDING RESILIENCE}

Throughout history, people and societies have adjusted to and coped with climate, climate variability, and extremes, with varying degrees of success. Adaptation is becoming embedded in planning processes, with more limited implementation of responses. Adaptation experience is accumulating. Governments at various levels are starting to develop adaptation plans and policies, and to integrate climate-change considerations into broader development plans.

Responding to climate-related risks involves decision-making in a changing world, with continuing uncertainty about the severity and timing of climate-change impacts and with limits to the effectiveness of adaptation. Adaptation and mitigation choices in the near-term will affect the risks of climate change throughout the $21^{\text {st }}$ century. Adaptation is place- and context-specific, with no single approach for reducing risks appropriate across all settings.

Adaptation planning and implementation can be enhanced through complementary actions across levels, from individuals to governments. 
A first step towards adaptation to future climate change is reducing vulnerability and exposure to present climate variability. Strategies include actions with co-benefits for other objectives. Adaptation planning and implementation are contingent on societal values, objectives, and risk perceptions. Poor planning, overemphasising short-term outcomes, or failing to sufficiently anticipate consequences can result in maladaptation.

Significant co-benefits, synergies, and tradeoffs exist between mitigation and adaptation, and among different adaptation responses. Increasing efforts to mitigate and adapt to climate change imply an increasing complexity of interactions, particularly at the intersections among water, energy, land use, and biodiversity. Examples of actions with co-benefits include:

- improved energy efficiency and cleaner energy sources, leading to reduced emissions of health-damaging and climate-altering air pollutants;

- reduced energy and water consumption in urban areas through the greening of cities and recycling of water;

- sustainable agriculture and forestry;

- protection of ecosystems for carbon storage and other ecosystem services.

Prospects for climate-resilient pathways for sustainable development are related fundamentally to what the world accomplishes with climate-change mitigation. Greater rates and magnitude of climate change increase the likelihood of adaptation limits being exceeded.

\section{MITIGATION OF CLIMATE CHANGE ${ }^{3}$}

Mitigation is human intervention to reduce the sources or enhance the sinks of greenhouse gases. Mitigation, together with adaptation to climate change, contributes to the objective expressed in Article 2 of the United Nations Framework Convention on Climate Change (UNFCCC):

The ultimate objective of this Convention ... is to achieve ... stabilization of greenhouse gas concentrations in the atmosphere at a level that would prevent dangerous anthropogenic interference with the climate system. Such a level should be achieved within a time frame sufficient to allow ecosystems to adapt naturally to climate change, to ensure that food production is not threatened and to enable economic development to proceed in a sustainable manner.

Yet determining whether such influence constitutes "dangerous anthropogenic interference" in the words of Article 2 of the UNFCCC involves both risk assessment and value judgments.

3 According to IPCC Assessment Report, 2014 (IPCC 2014b). 
Sustainable development and equity provide a basis for assessing climate policies and highlight the need for the risks of climate change to be addressed. Issues of equity, justice and fairness arise with respect to mitigation and adaptation.

Effective mitigation will not be achieved if individual agents advance their own interests independently.

Climate policy intersects with other societal goals, creating the possibility of co-benefits or adverse side-effects. These intersections, if well-managed, can strengthen the basis for undertaking climate action. Mitigation and adaptation can influence the achievement of other societal goals (e.g. those related to human health, food security, biodiversity, local environmental quality, energy access, livelihoods, and equitable sustainable development); and, vice versa, policies toward other societal goals can influence the achievement of mitigation and adaptation objectives.

Climate policy may be informed by consideration of a diverse array of risks and uncertainties, some of which are difficult to measure, notably low-probability, highimpact events.

The design of climate policy is influenced by how individuals and organizations perceive risks and uncertainties and take them into account.

\section{GREENHOUSE GAS EMISSIONS - PAST, PRESENT AND FUTURE}

About half of the cumulative anthropogenic $\mathrm{CO}_{2}$ emissions between 1750 and 2010 have occurred in the last 40 years. Cumulative $\mathrm{CO}_{2}$ emissions from fossil-fuel combustion, cement production and flaring since 1750 were $420 \pm 35$ GtCO2 in 1970 and tripled to $1300 \pm 110 \mathrm{GtCO} 2$ in 2010 .

The largest share of anthropogenic $\mathrm{CO}_{2}$ emissions is generated by a small number of countries. Ten countries accounted for about $70 \%$ of global $\mathrm{CO}_{2}$ emissions from fossil fuel combustion and industrial processes.

Annual anthropogenic GHG emissions have increased by $10 \mathrm{GtCO}$ eq between 2000 and 2010, with this increase directly coming from the sectors of energy supply $(47 \%)$, industry $(30 \%)$, transport (11\%) and buildings $(3 \%)$.

Despite climate change mitigation policies, annual GHG emissions grew by $1 \mathrm{Gt} \mathrm{CO} 2 \mathrm{eq}\left(\mathrm{CO}_{2}\right.$ equivalent) per annum from 2000 to 2010, as compared to 0.4 Gt CO2eq per annum from 1970 to 2010 .

Globally, economic and population growth continue to be the most important drivers of increases in $\mathrm{CO}_{2}$ emissions from fossil-fuel combustion. The contribution of population growth between 2000 and 2010 remained roughly identical to that in the previous three decades, while the contribution of economic growth has risen sharply. Between 2000 and 2010, both drivers outpaced emission reductions from improvements in energy intensity. Increased use of coal relative to other energy sources has reversed the gradual decarbonisation of the world's energy supply. 
Without additional efforts to reduce GHG emissions beyond those in place today, emissions growth is expected to persist, being driven by further growth in global population and economic activities. Baseline scenarios (i.e. those without explicit additional efforts to constrain emissions) exceed 450 parts per million (ppm) CO2eq by 2030 and reach CO2eq concentration levels between 750 and more than $1300 \mathrm{ppm}$ CO2eq by 2100. For comparison, the CO2eq concentration in 2011 is estimated to be 430 ppm (uncertainty range 340-520 ppm).

Delaying mitigation efforts beyond those in place today through 2030 is estimated to increase substantially the difficulty with the transition to low longer-term emissions levels, and to narrow the range of options consistent with maintaining temperature change below $2^{\circ} \mathrm{C}$. Estimates of the aggregate economic costs of mitigation vary widely and are highly sensitive to model design and assumptions, as well as the specification of scenarios, including the characterisation of technologies and the timing of mitigation. Scenarios in which all countries of the world begin mitigation immediately, there is a single global carbon price, and all key technologies are available, have been used as a cost-effective benchmark for estimating macroeconomic mitigation costs. Under these assumptions, mitigation scenarios that reach atmospheric concentrations of about 450ppm CO2eq by 2100 entail losses in global consumption - not including benefits of reduced climate change as well as co-benefits and adverse side-effects of mitigation - of $1 \%$ to $4 \%$ (median: $1.7 \%$ ) in $2030,2 \%$ to $6 \%$ (median: $3.4 \%$ ) in 2050 , and $3 \%$ to $11 \%$ (median: $4.8 \%$ ) in 2100 relative to consumption in baseline scenarios that grows anywhere from $300 \%$ to more than $900 \%$ over the century. These numbers correspond to an annualised reduction of consumption growth by 0.04 to 0.14 (median: 0.06) percentage points over the century relative to annualised consumption growth in the baseline that is between $1.6 \%$ and $3 \%$ per year.

Mitigation scenarios reaching about 450 or 500 ppm CO2eq by 2100 show reduced costs for achieving air-quality and energy-security objectives, with significant co-benefits for human health, ecosystem impacts, and sufficiency of resources and resilience of the energy system; these scenarios did not quantify other co-benefits or adverse side-effects. There are a wide range of possible adverse side-effects, as well as co-benefits and spillovers from climate policy that have not been well-quantified.

Mitigation efforts and associated costs vary between countries. The distribution of costs across countries can differ from the distribution of the actions themselves. In the baseline scenarios, direct $\mathrm{CO}_{2}$ emissions from the energy-supply sector are projected to almost double or even triple by 2050 compared with 2010, unless energy-intensity improvements can be accelerated significantly beyond the historical development.

\section{MITIGATION IN SECTORS}

Direct $\mathrm{CO}_{2}$ emissions from the energy-supply sector amounted to $14.4 \mathrm{GtCO} 2$ in 2010. Mitigation scenarios reaching around $450 \mathrm{ppm}$ CO2eq concentrations by 2100 show large-scale global changes in the energy-supply sector. Decarbonising (i.e. reducing 
the carbon intensity) of electricity generation is a key component of cost-effective mitigation strategies in achieving low-stabilization levels; in most integrated modelling scenarios, decarbonisation happens more rapidly in electricity generation than in the industry, buildings, and transport sectors. Carbon dioxide capture and storage (CCS) technologies could reduce the life-cycle GHG emissions of fossil-fuel power plants.

In 2010, the building sector was responsible for $8.8 \mathrm{Gt} \mathrm{CO}_{2}$ direct and indirect emissions, with energy demand projected to approximately double and $\mathrm{CO}_{2}$ emissions to increase by $50-150 \%$ by mid-century in baseline scenarios.

Recent advances in technologies, know-how and policies provide opportunities to stabilize or reduce global buildings-sector energy use by mid-century. For new buildings, the adoption of very low energy building codes is important, and has already progressed substantially. Retrofits form a key part of the mitigation strategy in countries with established building stock, and huge reductions in heating/cooling energy use in individual buildings have been achieved.

Lifestyle, culture and behaviour influence energy consumption in buildings significantly. A three- to five-fold difference in energy use has been shown for provision of similar building-related energy service levels in buildings. For developed countries, scenarios indicate that lifestyle and behavioural changes could reduce energy demand by up to $20 \%$ in the short term, and by up to $50 \%$ of present levels by mid-century. In developing countries, integrating elements of traditional lifestyles into building practices and architecture could facilitate the provision of high levels of energy services with much lower energy inputs than baseline.

In 2010, the industry sector was responsible for $13 \mathrm{Gt} \mathrm{CO}_{2}$ of direct and indirect emissions as well as process emissions, with emissions projected to increase by $50-150 \%$ by 2050, unless energy efficiency improvements are accelerated significantly.

The Agriculture, Forestry and Other Land Use (AFOLU) sector accounts for about a quarter $(\sim 10-12 \mathrm{GtCO} 2 \mathrm{eq} / \mathrm{yr})$ of net anthropogenic GHG emissions, mainly from deforestation, agricultural emissions from soil and nutrient management and livestock. Recent estimates indicate a decline in AFOLU $\mathrm{CO}_{2}$ fluxes, largely due to decreasing deforestation rates and increased afforestation.

Bioenergy can play a critical role in mitigation, but such issues as the sustainability of practices and the efficiency of bioenergy systems have to be resolved.

In 2010, the transport sector was responsible for $6.7 \mathrm{Gt} \mathrm{CO}_{2}$ of direct emissions, with baseline $\mathrm{CO}_{2}$ emissions projected to approximately double by 2050 .

Urbanisation is expected to continue to be a major driver of energy use.

\section{FINAL REMARKS}

It is hoped that the present article will encourage the part of readership who have not seen IPCC AR5 yet, to dive into this already-available document that provides a wealth of information. 
This present paper, reporting on the most essential findings in AR5, has been finalised in May 2014. It has been prepared without access to the AR5 Synthesis Report, i.e. a very serious, formal, document prepared collectively - compiled by dozens of scientists as authors and reviewed by hundreds of referees over more than a year. The present paper is thus a much simpler, subjective view from a single scientist. However, from June 2014 on the author of this present paper had access, as a Review Editor of the IPCC AR5 Synthesis Report, to a draft of the Synthesis Report and many related comments of governmental reviewers made available. Hence, preparation of the present paper was a warm-up to the work of a Review Editor of the Synthesis Report, which was launched in November 2014.

\section{ACKNOWEDGMENTS}

The author wishes to thank Professor Małgorzata Gutry-Korycka who invited him to prepare a paper based on his oral presentation on IPCC AR5 delivered at a session of the Global Change Committee of the Polish Academy of Sciences. The author acknowledges the collective effort of many experts who prepared the IPCC Fifth Assessment Report, being the principal source of knowledge in his work on this paper.

\section{REFERENCES}

IPCC, 2013, Summary for Policymakers, [in:] Climate Change 2013: The Physical Science Basis, Contribution of Working Group I to the Fifth Assessment Report of the Intergovernmental Panel on Climate Change, T.F. Stocker, D. Qin, G.-K. Plattner, M. Tignor, S.K. Allen, J. Boschung, A. Nauels, Y. Xia, V. Bex and P.M. Midgley (eds), Cambridge University Press, Cambridge, United Kingdom and New York, NY, USA.

IPCC, 2014a, Summary for Policymakers, [in:] Climate Change 2014: Impacts, Adaptation, and Vulnerability, Contribution of Working Group II to the Fifth Assessment Report of the Intergovernmental Panel on Climate Change, C.B. Field, V.R. Barros, M.D. Mastrandrea, K.J. Mach (eds), Cambridge University Press, Cambridge, United Kingdom and New York, NY, USA.

IPCC, 2014b, Summary for Policymakers, [in:] Climate Change 2014, Mitigation of Climate Change, Contribution of Working Group III to the Fifth Assessment Report of the Intergovernmental Panel on Climate Change, O. Edenhofer, R. Pichs-Madruga, Y. Sokona, E. Farahani, S. Kadner, K. Seyboth, A. Adler, I. Baum, S. Brunner, P. Eickemeier, B. Kriemann, J. Savolainen, S. Schlömer, C. von Stechow, T. Zwickel and J.C. Minx (eds), Cambridge University Press, Cambridge, United Kingdom and New York, NY, USA.

Nakićenović, N., and Swart, R., (ed.), 2000, Emission Scenarios. A special report of Working Group III of the Intergovernmental Panel on Climate Change, Cambridge University Press, Cambridge, United Kingdom and New York, NY, USA. 